\title{
Como Simplificar o Trabalho
}

\section{José RodRIGues dE SENNA}

\section{A ATIVIDADE DE O \& M NA ADMINISTRAÇÃO PÚBLICA}

\begin{abstract}
A aplicação de métodos científicos de aperfeiçoamento da administração pública, em escala generalizada, foi decorrência de pressões da șegunda guerra. Os países envolvidos nesse conflito tiveram de enfrentar o sério problema de atender a grande aumento de tarefas administrativas e, ao mesmo tempo, à necessidade de economizar esfôrço humano para as operações de guerra. Nada mais natural, portanto, do que recorrer à experiência no campo das atividades privadas, no qual já se vinha, de longa data, aplicando com êxito métodos para fazer as coisas com menor esfôrço, menor custo e em menos tempo.
\end{abstract}

Se quisermos indagar das origens técnicas do movimento moderno de aperfeiçoamento da administração pública, iremos encontrá-las em sistemas tais como o fayolismo, na França, o taylorismo, nos Estados Unidos, o estacanovismo, na Rússia, a racionalização, na Alemanha, a ergologia, na Bélgica. Todavia, êsse novo movimento da administração pública apresenta características próprias, entre as quais se destaca a atenção aos problemas de relações humanas.

Esse movimento de melhoria originou na administração pública nova atividade especializada, em geral denominada organização e métodos, ou simplesmente - O \& $\mathrm{M}$, segundo a prática inglêsa. A atividade $\mathrm{O} \& \mathrm{M}$, visa à economia e à eficiência na administração, através do contrôle dos fatôres determinantes da eficácia ou ineficácia da organização. Assim, ela está voltada para aspectos tais como: estrutura de autoridade, divisão do trabalho, seqüência do trabalho, sistemas de comunicações, uso de materiais e equipamentos, distribuição de espaço, simplificação de métodos, utilização de pessoal, localização de sedes, disposição interna, condições físicas dos locais de trabalho, contrôle de qualidade, elaboração e uso de formulários, manutenção de arquivos, contrôle de custo, etc.

$\mathrm{O}$ desempenho da atividade de $\mathrm{O} \& \mathrm{M}$ exige, como fàcilmente se percebe pela variedade e complexidade de seu campo de ação, a instituição de órgão próprio dotado de pessoal especializado. Todavia, tal órgão não pode exercer monopólio da atividade, sob pena de fracasso. A existência de um órgão de $\mathrm{O} \& \mathrm{M}$ é justificada apenas pela necessidade de prestar assistência às chefias dos diversos órgãos executivos. A essas chefias é que compete, realmente, a 
função de $\mathrm{O} \& \mathrm{M}$, o dever de aperfeiçoar constantemente os sistemas e métodos de trabalho.

É importante, entretanto, que todo supervisor compreenda bem o papel de um órgão de $\mathrm{O} \& \mathrm{M}$, a fim de que possa tirar bom partido dêle no desempenho de sua responsabilidade individual de aperfeiçoar contìnuamente o serviço a seu cargo. Nem sempre o chefe dispõe de tempo e recursos para realizar certos tipos de estudos. O setor de $\mathrm{O} \& \mathrm{M}$ é um aliado valioso do chefe nessas ocasiões e, a não ser que esteja deturpando a razão de ser de sua existência, tal setor trabalhará com o chefe e para o chefe que recorrer aos seus serviços.

Esse movimento de aperfeiçoamento da administração pública através da atividade de $\mathrm{O} \& \mathrm{M}$, da qual participam os próprios supervisores, por um lado, e o órgão de $\mathrm{O} \& \mathrm{M}$, de outro, em bases cooperativas, tem apresentado resultados altamente compensadores. Menciona-se, por exemplo, que o Quarter Master Corps do Exército Americano conseguiu uma redução de 16.298 empregados, num ano apenas de aplicação de técnicas de simplificação de trabaIho. Isto se deu justamente na ocasião da guerra, quando o intenso aumento do volume do trabalho burocrático estava exigindo grande acréscimo do quadro de pessoal. Diz-se, também, que nas repartições do Exército Americano o programa de simplificação resultou na eliminação de 834 formulários e registros desnecessários.

O programa de $\mathrm{O} \& \mathrm{M}$ na administração pública canadense proporcionava, em 1952, uma economia anual estimada em $\$ 5.000 .000$. Enquanto isto, o custo do programa era avaliado em $\$ 75.000$. A Divisão de Pagamento do Tesouro Americano contava, em 1947, com um quadro de 3.735 funcionários, e preparava 160 milhões de cheques; em 1950 o número de funcionários era de 3.472 (263 a menos), e o volume de cheques havia subido para 186 milhões (256 milhões a mais). Êste último exemplo ilustra bem a idéia de contrabalançar o crescimento do volume, através da atividade de O \& $\mathrm{M}$.

A primeira impressão poderá ser de que tais resultados sejam determinados por inovações revolucionárias e modificações rad cais. A verdade, entretanto, é que isso ocorre muito raramente. Não são muito freqüentes cascs como o do Bureau of Internal Revenue americano, que introduziu uma nova calculadora eletrônica com capacidade para efetuar, por hora, cêrca de 6.000 cálculos de impostos devidos.

A atividade de $O \& \mathrm{M}$ produz bons resultados através do efeito cumulativo e continuado de pequenos aperfeiçoamentos em todos os níveis e aspectos do trabalho de uma organização. Existem possibilidades quase infinitas dêsses pequenos aperfeiçoamentos. A eliminação de um ou mais passos numa rotina; a combinação de formulários com dados comuns; a estandardização de um registro repetitivo; a liberação de funcionários especializados de tarefas mecânicas; o uso de um equipamento ou recurso mecânico para reduzir o tempo de execução de uma tarefa manual; a redução de frequêencia de erros pela elaboração de padrões de conformidade; a eliminação de documentos sem valor nos arquivos; a disposição apropriada de meios para eliminar movimentos desnecessários; o uso de símbolos e códigos para reduzir o trabalho 
de escrita; a eliminação de duplicações e pontos de congestionamento, são exemplos típicos de áreas de aperfeiçoamento sôbre as quais todo supervisor pode exercer sua influência.

\section{SIMPLIFICAÇÃO DO TRABALHO PELO PRÓPRIO CHEFE}

Importante realização dos especialistas de $\mathrm{O}$ \& $\mathbf{M}$ na administração pública, nestes últimos anos, foi a de terem desenvolvido uma técnica de análise e simplificação do trabalho acessível a qualquer supervisor medianamente qualificado. O significado dessa realização é fácil de perceber. Até aqui, a importantíssima função de aperfeiçoamento da organização e dos métodos de trabalho constituía como que um privilégio de pequeno número de iniciados nas técnicas de análise administrativa. Atualmente, qualquer instituição que o deseje tem a possibilidade de utilizar os próprios chefes como especialistas de $\mathrm{O} \& \mathrm{M}$. Com isto se pode conseguir muito mais do que com o mais perfeito e especializado dos órgãos de $\mathrm{O} \& \mathrm{M}$.

A idéia de fazer o próprio chefe participar da atividade de $\mathrm{O} \& \mathrm{M}$ se funda em razões muito ponderosas. Em primeiro lugar, é reconhecido que o aperfeiçoamento da organização e dos métodos de trabalho constitui responsabilidade precípua do chefe. Além disso, o chefe está em posição muito favorável para exercer essa atividade, quer por ter, melhor que ninguém, conhecimentos práticos do serviço, quer por estar em contáto direto com os funcionários, podendo, assim, mais fàcilmente obter a receptividade e a participação dos mesmos. Um especialista estranho ao grupo de trabalho geralmente não conta com essa vantagem.

A implantação de um programa de simplificação do trabalho a cargo dos chefes requer preparação sistemática e cuidadosa. Há diversos aspectos que precisam ficar bem reconhecidos e aceitos, tanto pela administração, como pelo próprio corpo de supervisores e do funcionalismo em geral.

De início, é essencial o reconhecimento de que não se trata de tarefa temporária, de algo que o chefe vai fazer a título de serviço extraordinário, que uma vez concluido deixará de constituir objeto de suas cogitações diárias. Tal concepção seria inteiramente falsa. Trata-se de implantar algo permanente, de dotar o chefe de um instrumento de trabalho a ser usado permanentemente, continuamente, tal como êle usa diàriamente sua mesa, sua caneta, sua pasta de instruções. O sucesso do programa depende da continuidade, da preocupação constante do chefe em analisar o trabalho, em identificar sempre novas possibilidades de simplificação e melhoria, tal como o chefe se preocupa diàriamente em verificar se a produção de seu setor está correndo a contento, se as partes estão sendo bem atendidas, se os funcionários dispõem do material e dos meios necessários, etc.. As técnicas de análise e simplificação do trabalho representam, na realidade, técnicas modernas de chefia, meios eficazes para obter bons resultados, para economizar tempo, esfôrço e dinheiro.

Outra condição básica de sucesso do programa de simplificação a cargo dos chefes é a de sistematização, de método. É imperioso abandonar os processos de improvisação e de modificações apressadas dos sistemas de traba- 
1ho. E preciso combater o inveterado hábito das transformações radicais e revolucionárias, sem o apôio de cuidadoso, ordenado e objetivo trabalho de coleta, classificação, registro e análise dos fatos de cada situação. O programa de simplificação a cargo dos chefes tem uma de suas características fundamentais na idéia de melhorar o trabalho através do efeito cumulativo e continuado de pequenos aperfeiçoamentos, sempre ditados pelo conhecimento organizado, ordenado, dos fatos da situação. Êste programa pode não ser o que produza resultados espetaculares para os grandes cartazes. A experiência tem demonstrado, entretanto, ser êle o que produz, através do tempo, os resultados mais duradouros e eficazes.

É essencial que o funcionalismo seja convenientemente informado sôbre os objetivos e vantagens do programa, a fim de que também participe dêle. Assim como um especialista sem a cooperação dos chefes pouco conseguirá, também o chefe sem a participação interessada do funcionalismo pouco realizará de proveitoso e duradouro. Deve-se mostrar aos funcionários que o programa não envolve qualquer ameaça à sua segurança e bem-estar. Muito pelo contrário, o programa contribuirá para fortalecer essa segurança porque, por exemplo, reduzirá a necessidade de aumentos do quadro de pessoal, que poderão importar na redução de vantagens; que o programa tem em vista tornar o trabalho mais confortável, equilibrando a distribuição de tarefas, controlando fatôres que dificultam a execução, proporcionando meios adequados, utilizando melhor as aptidões de cada um, etc.

Os próprios chefes precisam capacitar-se também das vantagens que êsse programa lhes proporciona. Uma dessas vantagens é, sem dúvida, a valorização profissional. Como se está tornando reconhecido cada vez mais, o chefe moderno precisa de formação especializada. Boa evidência dêsse reconhecimento é o aumento do número de cursos de formação de chefes, hoje em dia oferecidos por instituições públicas e particulares, e objeto de anúncios diários nos jornais. O programa de simplificação do trabalho, pela objetividade e caráter prático com que é implantado, corresponde ao melhor dos cursos de chefia, pois nêle se aprendem as técnicas aplicando, em vez de através de meras exposições verbais e teóricas. Por outro lado, essas técnicas são as mesmas que os cursos e escolas de administração em todo o mundo incluem em seus programas de organização e métodos. São as mesmas, também, que os escritórios de consultores de organização utilizam em suas atividades de racionalização do trabalho, e que cada dia ganham mais aceitação em nosso meio, para não falar nos países mais adiantados, cnde já fazem parte normal do conjunto de instituições profissionais.

Todavia, a maior vantagem do programa para os chefes é o aumento de eficiência que o mesmo proporciona, tornando o trabalho de chefia muito mais fácil, seguro e sistematizado.

O apôio da administração ao programa representa condição basilar. É essencial que a administração, em todos os níveis, realmente deseje que o programa se realize. Tal apôio deve traduzir-se em medidas concretas, tais como manifestação expressa de interêsse pessoal dos chefes superiores, através de documentos e reuniões, acompanhamento da marcha do programa, facilitação de meios. 
E necessário que os chefes contem com assistência adequada no período de implantação do programa. Para êsse fim, é preciso que a administração designe funcionários qualificados, a cargo dos quais ficará a tarefa de orientação inicial. Além disso, êsse grupo de funcionários orientadores deve encarregar-se de promover qualquer providência sugerida pelos chefes, como resultado de suas análises, mas que estejam fora de seu âmbito de ação.

A avaliação do progresso do programa é outro requesito indispensável. Essa avaliação precisa ser feita em bases tão objetivas quanto possível, de forma a mostrar a extensão em que o programa vem contribuindo realmente para reduzir o tempo, o esfôrço e o custo dos serviços, e para melhorar a qualidade. Não teria sentido coletar fatos e elaborar gráficos, se êstes não produzissem resultados significativos em tôrno de melhoria do serviço. O sistema de avaliação deve possibilitar a visualização das economias conseguidas em funcionários-horas, espaço, material, bem como deve indicar a forma pela qual essas economias foram aplicadas. Além disso, é desejável que essa avaliação mostre o desempenho comparado dos diversos setores, a fim de permitir que a administração dirija suas vistas para as áreas necessitadas de maior assistência.

A necessidade de planejar a implantação em cada setor requer atenção. Impõ-se a fixação de prazos para o cumprimento das diversas fases da análise, sem o que a tendência para o adiamento poderá prejudicar o programa. As datas para reuniões devem ser marcadas com antecedência adequada. A pre visão, o preparo e a distribuição do material a ser utilizado têm de ser provi denciados. A escolha de setores, a indicação de orientadores, a escolha de locais de reuniões, o estabelecimento de contrátos prévios com as chefias de diferentes graus que estejam ligados aos setores escolhidos, representam exemplos de tópicos a serem considerados na fase de planejamento.

E desejável, segundo pensamos, procurar-se inicialmente seguir os padrões técnicos recomendados pelos especialistas, e já experimentados com êxito. Essa observação decorre da tendência entre nós para se inventarem coisas que já estảo inventadas, resultando daí grande perda de tempo e esfôrço. Técnicos em organização, principalmente nos Estados Unidos e Inglaterra, têm dedicado grande atenção a êsse assunto. As técnicas preconizadas por êsses especialistas estão descritas com detalhes em vários manuais de repartições americanas, como por exemplo os do Bureau de Orçamento, e em inúmeras publicações especializadas. O Instituto de Ciências Administrativas de Bruxelas, por exemplo, publicou, em 1953, um folheto para as Nações Unidas, intitulado $A$ Work Simplification Program, no qual estão suficientemente descritas as técnicas a que me refiro. O fato de que a Organização das Nações Unidas esteja interessada na divulgação dessas técnicas é indício de sua aplicabilidade a diferentes meios. Não desejamos, com isso, advogar uma orientação rígida, mas tão sòmente sugerir que nenhuma alteração substancial dêsse padrão técnico seja feita enquanto não tivermos um cabedal razoável de dados de nossa experiência, em face do qual possamos, se necessário, adaptá-lo às condições peculiares de nosso meio.

Há um problema um tanto delicado na fase de implantação que exige atenção especial. Trata-se da alegação generalizada da falta de tempo pelos 
chefes. É realmente difícil modificar de um dia para outro um hábito de trabalho arraigado. Freqüentemente os chefes de primeira linha, isto é, os que têm sob sua responsabilidade direta a fase pròpriamente dita de execução, dificilmente conseguem fugir à tendência de se absorverem nessa execução. Muitos chefes são, na realidade, funcionários executores de tarefas, muitas das quais meramente rotineiras. Esse fato cria um círculo vicioso. O chefe não tem tempo para analisar, planejar, programar e simplificar o trabalho. Com isso, mais se avoluma e complica o trabalho, e mais êle se absorve na massa. A única maneira de cortar êsse círculo vicioso é justamente a implantação de um programa sistemático de análise e simplificação do trabalho. O tempo que êsse programa exige inicialmente do chefe é relativamente pequeno. Segundo a experiência americana, a implantação do programa é feita em três semanas, com um total de 12 horas de trabalho pelos chefes, ou sejam, 4 horas por semana. Sòmente três das 12 horas são consumidas em reuniões para explicação e debates das técnicas de análise e simplificação. As 9 horas restantes são empregadas pelos chefes no trabalho pròpriamente dito de análise e simplificação, sob a assistência dos orientadores do programa.

\section{PROGRAMA DE SIMPLIFICAÇÃO DO TRABALHO NO I.A.P.I.}

Em 1954 o Instituto dos Industriários iniciou em alguns setores, a título de experiência, um programa de simplificação do trabalho a cargo dos próprios chefes. Nesse programa adotou-se o sistema do serviço público americano, o qual se acha minuciosamente descrito numa série de manuais do Bureau de Oraçmento dos Estados Unidos (U. S. Government: Work simplification Program; U. S. Government Printing Office, Washington 25. D.C.)

Os resultados dessa experiência levaram a Administração do I.A.P.I. a adotar a simplificação do trabalho como atividade sistemática, permanente e obrigatória em todos os setores do Instituto. Para isso, foi expedida uma Resolução de Serviço pelo Presidente, na qual foram estabelecidas as bases de organização e de funcionamento da nova atividade. Além disso, foi aprovado um manual destinado a orientar os chefes no emprêgo das técnicas de simplificação do trabalho, utilizando-se exemplos ilustrativos tirados da própria experiência do Instituto.

Antes de passarmos à apresentação do referido manual, focalizaremos sumàriamente as principais bases da organização e do funcionamento da atividade de simplificação do trabalho no I.A.P.I. .

A atividade de simplificação foi incorporada ao rol dos deveres e responsabilidades normais dos chefes de todos os níveis hierárquicos. Cabe ae Chefe da Seção a execução pròpriamente dita da simplificação. Todavia, a supervisão deverá ser efetuada pelo Chefe de Divisão ou de Serviço, pelo Chefe de Órgão Central ou Local, e, finalmente, êstes são responsáveis perante o Presidente, quanto ao desempenho e aos resultados da atividade de simplificação. Tal como acontece, portanto, em relação às outras funções dos chefes .

A fim de auxiliar o Presidente na supervisão e coordenação gerais da atividade foi designado um dos assistentes técnicos de seu Gabinete. 
O sistema de orientação técnica foi planejado de maneira a evitar a interferência de elementos estranhos em cada órgão. Esta preocupação dispensa comentários. A idéia dominante é que a simplificação seja realmente uma função normal do próprio chefe.

A tarefa de assegurar uniformidade do sistema está afeta à Divisão de Organização e Métodos no Departamento de Serviço Gerais. Esta Divisão, constituída de pequeno grupo de especialistas (seis), tem a função principal de clearing-house, isto é, promover a troca e a difusão de idéias e experiências, com vistas à uniformidade de métodos. Além disso, a Divisão realiza projetos especiais, com base em programa aprovado semestralmente.

Dentro de cada Órgão Central foi designado um dos respectivos Assistentes Técnicos, para dedicar-se à função de organização e métodos. A êsse Assistente cabe a orientação e a supervisão técnica do programa de simplificação dentro do Órgão Central, e serve junto ao chefe do órgão.

Em cada Divisão ou Serviço a tarefa de orientação e supervisão técnica destacar um Assessor, foi designado um Auxiliar de Organização e Métodos, com a função de auxiliar o Chefe da Divisão ou Serviço na tarefa de orientação e supervisão técnica.

A implantação do programa de simplificação obedece às seguintes bases:

- o trabalho é dividido em quatro fases (ver manual);

- é estabelecido um prazo de duas semanas para cada uma das três primeiras fases, e de três semanas para a fase final (planejamento das simplificações);

- cada fase é precedida de uma reunião geral dos Assistentes de Organização e Métodos dos Órgãos Centrais, presidida pelo Assistente Coordenador do Gabinete do Presidente, e com a participação da Divisão de Organização e Métodos; nessa reunião debatem-se as normas, com base no manual, e se programam as atividades para implantação e execução da fase em cada Órgão;

- em seguida, cada Assistente realiza uma reunião com os Assessores ou Auxiliares de Organização e Métodos do respectivo Órgão Central;

- finalmente, cada Assessor ou Auxiliar realiza reunião preparatória com os Chefes de Seção da Divisão ou Serviço, sempre que possível presidida pelo respectivo Chefe;

- durante a execução de cada fase se realiza o trabalho de acompanhamento, estabelecendo-se freqüentes contatos informais entre os Assessores ou Auxiliares com os Chefes de Seção, daqueles com os Assistentes, e, finalmente, dêsses com a Divisãc de Organização e Métodos, para efeito de consultas e troca de idéias; os Chefes de Divisão ou Serviço, por outro lado, verificam o cumprimento de prazos e o andamento geral dos trabalhos, não só através de observações diretas mas de informações dos Assessores ou Auxiliares;

- concluídos os trabalhos de cada fase, realiza-se nova série de reuniões para efeito de apreciação dos resultados; estas reuniões se efetuam, porém, em sentido inverso das preparatórias, isto é, se iniciam com os Assessores ou 
Auxiliares com os Chefes de Seção, daqueles com os Assistentes, e, finalmente, dêstes com o Coordenador e a Divisão de Organização e Métodos.

As decisões sôbre simplificações a adotar são da competência das chefias dos diferentes níveis hierárquicos. Cada simplificação importante é objeto de um relatório sucinto, preparado em modêlo próprio pelo Chefe de Seção (ver Fase 4 do manual). Sempre que esteja na alçada do próprio Chefe de Seção, êste decidirá adotar a simplificação, e dará ciência disso ao Chefe de Divisão ou Serviço, que aporá o visto no relatório da simplificação. Se não estiver na alçado do Chefe de Seção, o relatório será encaminhado, através da chefia, à autoridade competente para autorizar a modificação, a qual expedirá os atos necessários.

A apuração dos resultados do programa é feita da seguinte maneira:

-- o Assistente de cada Órgão recebe, mensalmente, cópia dos Relatórios de Simplificação preparados pelos Chefes de Seção, e providencia o preparo de um relatório do Órgão, no qual aparecem as estimativas de funcionários-hora e de material economizados por setor, em conseqüência das simplificações, destacando as adotadas e, as dependentes de aprovação;

- o Assistente Coordenador do Gabinete do Presidente recebe mensalmente dos Assistentes cópia do relatório de cada Órgão, e promove, através da Divisão de Organização e Métodos, o preparo de um relatório geral condensado, a ser submetido ao Presidente;

A manutenção do programa de simplificação do trabalho, uma vez concluída a implantação, obedecerá ao seguinte plano:

- cada Chefe de Seção terá um programa de trabalho semestral de organização e métodos, ao qual deverá dedicar um número mínimo de horas por semana; êsse programa compreenderá não só as atividades e tarefas que não tenham sido estudadas com profundidade na fase de implantação, como também certos estudos de caráter geral, planejados em reuniões dos Assistentes com o Coordenador e a Divisão de Organização e Métodos (por exemplo: análise de correspondência, análise de formulários, estudo de utilização de espaço e lay-out, etc.);

- o Chefe de Seção continuará a preparar Relatórios de Simplificação sempre que introduzir melhorias no serviço, e manterá sempre atualizados o Quadro de Distribuição do Trabalho e os Gráficos de Sequêencia das rotinas (ver manual);

- os Assessores ou Auxiliares de Organização e Métodos terão pelo menos uma reunião por mês com os Chefes de Seção das respectivas Divisões ou Serviços, e com o Assistente de Organização e Métodos do Órgão para debater o andamento do programa;

- haverá também, pelo menos uma vez por mês, uma reunião geral dos Assistentes de Organização e Métodos com o Coordenador do Gabinete do Presidente e a Divisão de Organização e Métodos sôbre o programa a cargo dos Chefes de Seção;

- além do programa de trabalho a cargo dos Chefes de Seção, haverá um programa semestral de organização em métodos a cargo dos Assistentes e 
dos Assessores ou Auxiliares; êsse programa compreenderá principalmente o estudo das rotinas que envolvam várias Seções de um mesmo órgão, ou de Órgãos diferentes; haverá pelo menos uma reunião mensal dos Assistentes com o Coordenador e a Divisão de Organização e Métodos, para tratar dêsse programa;

- a apuração de resultados será mensal e nas mesmas bases do sistema adotado na implantação.

A título de intercâmbio de experiências a Divisão de Organização e Métodos coletará, por intermédio dos Assistentes de Organização e Métodos, casos típicos de simplificações para publicação e divulgação; promoverá, ainda, a publicação de informações e observações que possam contribuir para aumentar a eficácia do programa e a uniformidade de procedimentos.

O sistema de incentivo consistirá principalmente na concessão de prêmios a indivíduos ou a grupos que mais tenham contribuído, em cada ano, para a eficiência dos serviços do Instituto. A idéia de premiar grupos interessa particularmente à Administração, com o objetivo de desenvolver o espírito de equipe. Considera-se altamente desejável que os chefes motivem os funcionários das respectivas Seções a sugerir simplificações. A apuração, para efeito de prêmios, será feita com base em exame dos Relatórios de Simplificações, complementado por observações diretas, se necessário. Essa apuração será feita por uma Comissão especialmente designada, a qual será assessorada pela Divisão de Seleção e Assistência e a Divisão de Organização e Métodos.

O Manual de Simplificação do Trabalho, cuja publicação iniciaremos no presente número, está dividido em quatro partes:

Fase. 1 - Análise da Distribuição do Trabalho.

Fase 2 - Análise da Seqüência do Trabalho.

Fase 3 - Análise do Volume do Trabalho.

Fase 4 - Planejamento das Simplificações.

Nos números seguintes publicaremos as Fases restantes. 